\title{
Factors Affecting Medical Students' Uptake of the 2009 Pandemic Influenza A (H1N1) Vaccine
}

\author{
Siang I. Lee, ${ }^{1}$ Ei M. Aung, ${ }^{1}$ Ik S. Chin, ${ }^{1}$ Jeremy W. Hing, ${ }^{1}$ Sanghamitra Mummadi, ${ }^{1}$ \\ Ghunavadee D. Palaniandy, ${ }^{1}$ and Rachel Jordan ${ }^{2}$ \\ ${ }^{1}$ College of Medical and Dental Sciences, University of Birmingham, Edgbaston, Birmingham B15 2TT, UK \\ ${ }^{2}$ Unit of Public Health, Epidemiology and Biostatistics, School of Health and Population Sciences, College of Medical and \\ Dental Sciences, Public Health Building, University of Birmingham, Edgbaston, Birmingham B15 2TT, UK
}

Correspondence should be addressed to Rachel Jordan, r.e.jordan@bham.ac.uk

Received 21 April 2012; Accepted 26 July 2012

Academic Editor: Ian Barr

Copyright (๑) 2012 Siang I. Lee et al. This is an open access article distributed under the Creative Commons Attribution License, which permits unrestricted use, distribution, and reproduction in any medium, provided the original work is properly cited.

\begin{abstract}
Background. Pandemic influenza vaccination rate amongst healthcare workers in England 2009/2010 was suboptimal (40.3\%). Targeting medical students before they enter the healthcare workforce is an attractive future option. This study assessed the H1N1 vaccine uptake rate amongst medical students and factors that influenced this. Methods. Anonymised, self-administered questionnaire at a medical school. Results. The uptake rate amongst 126 medical students offered the vaccine was $49.2 \%$ and intended uptake amongst 77 students was 63.6\%. Amongst those offered the vaccine, the strongest barriers to acceptance were fear of side effects (67.9\%), lack of vaccine information (50.9\%), lack of perceived risk (45.3\%), and inconvenience (35.8\%). Having a chronic illness (OR 3.4 (95\% CI 1.2-10.2)), 4th/5th year of study (OR 3.0 (95\% CI 1.3-7.1)), and correct H1N1 knowledge (OR $2.6(95 \%$ CI 1.1-6.0)) were positively associated with uptake. Non-white ethnicity was an independent negative predictor of uptake (OR $0.4(95 \%$ CI 0.2-0.8)). Students who accepted the H1N1 vaccine were three times more likely (OR 3.1 (95\% CI $1.2-$ 7.7)) to accept future seasonal influenza vaccination. Conclusion. Efforts to increase uptake should focus on routine introduction of influenza vaccine and creating a culture of uptake during medical school years, evidence-based education on vaccination, and improving vaccine delivery.
\end{abstract}

\section{Introduction}

The novel influenza A (H1N1) outbreak was declared a pandemic by the World Health Organisation (WHO) on 11th June 2009 [1]. In the United Kingdom (UK), 474 deaths had occurred by the end of the 2009/10 influenza season with the highest case-fatality rate among the over 65 -year age group $[1,2]$. Vaccination is one of the intervention strategies used to mitigate an influenza pandemic [3, 4]; therefore, as part of the Department of Health (DH) vaccination policy healthcare workers were recommended to receive the $\mathrm{H} 1 \mathrm{~N} 1$ vaccine to protect themselves, protect patients, and maintain frontline services during the pandemic $[5,6]$. At the University of Birmingham, clinical year (3rd-5th year) medical students were also offered the H1N1 vaccine from November 2009 [7].
Influenza vaccination of health care workers (HCW) is known to be effective in preventing seasonal influenza, reducing absenteeism, and protecting patients against nosocomial infection with a resultant decrease in morbidity and mortality $[6,8]$. In spite of these benefits, seasonal influenza vaccine uptake among HCW in the UK has traditionally been disappointingly low with uptake of less than $20 \%$ in the pre-pandemic year of 2008/2009 in the UK [9]. Similarly low uptake rates have been reported in many other European countries [10]. During the pandemic year, there was a slight increase of HCW seasonal influenza vaccine uptake from $16.5 \%$ to $26.4 \%$, while pandemic influenza vaccine uptake among HCW reached $40.3 \%$ in the UK [9].

However, vaccine uptake amongst HCW remains suboptimal. It has been frequently found that previous history 
of seasonal influenza vaccination is a strong predictor of both seasonal and H1N1 vaccine uptake [11-15]. Although no studies have shown a correlation between H1N1 vaccine uptake with subsequent seasonal influenza uptake, figures in England showed an increase in the latter after the H1N1 pandemic [16]. Achieving a high vaccine uptake in the early stages of a medical career might therefore improve subsequent influenza vaccine uptake as suggested by Amodio et al. [17]. Previous studies have shown suboptimal influenza uptake amongst medical students (USA 48\% [18], Hong Kong $67 \%$ [19]). Since medical students in the UK are not routinely offered the influenza vaccine and nor are there data on their influenza vaccine uptake, the pandemic situation allowed us to determine H1N1 influenza vaccine uptake in this group and identify key factors influencing this. As they are HCW of the future, maximising uptake by addressing barriers in this population may help improve subsequent uptake rates.

\section{Materials and Methods}

2.1. Study Design. This was a cross-sectional study carried out between February and March 2010 using an anonymised self-completed questionnaire.

2.2. Subjects and Setting. The sample population consisted of 481 out of more than a thousand medical students from the University of Birmingham. 40 subjects were Graduate Entry Course 1 (GEC1) students, 70 were from year 2, 194 from year 3, 60 from year 4 and 117 from year 5. This population was selected and allocated randomly by study group by the Project Scrutiny Committee of the College of Medical and Dental Sciences, University of Birmingham. Initially, a link to the questionnaire was emailed to the allocated sample with a reminder sent after a week. The web-based survey was open for two weeks. Owing to a poor response rate using this method, paper questionnaires were subsequently distributed to the originally allocated sample and to a convenience sample of students that were on similar hospital placement as the authors. These were distributed to the selected year 2 students during their tutorials and to years $3-5$ students at their respective hospital placements.

2.3. Influenza Immunisation Programme. Medical students were made aware of the availability of the pandemic influenza vaccine via notices posted on the student notice boards, emails from the hospitals where students were placed and a general email from the medical school. The vaccine was not formally offered to the medical student cohort as a whole, rather it was offered opportunistically by some hospital trusts depending on each hospital's policy.

The hospital trusts allocated a set date, time, and location where medical students could receive the vaccination from trained staff during their hospital placements. Seasonal influenza vaccination was offered simultaneously. Both vaccines were available free of charge.
2.4. Questionnaire. The questionnaire (see the appendix) collected sociodemographic data (age; sex; year of study; history of chronic illness; living with specified groups including children under 16 , pregnant woman, over 65 's, and healthcare workers), information regarding smoking status, previous seasonal influenza vaccination and adverse reactions, perceived severity of swine flu, reasons for and against H1N1 immunisation, influences affecting immunisation, and three knowledge items related to swine flu. Reasons for and against vaccination were adapted from questionnaires used in previous papers $[12,20,21]$. Participants were prompted to rank three reasons for acceptance or declination and three major influences. Since a significant number of respondents failed to rank their responses, we did not analyse the result according to rank. The questionnaire was piloted prior to the study.

2.5. Outcomes. The primary outcome was receipt of $\mathrm{H} 1 \mathrm{~N} 1$ vaccine, but for those not offered $\mathrm{H} 1 \mathrm{~N} 1$ vaccine, there was an option to reply with "intention to vaccinate".

2.6. Statistical Analysis. Analysis was performed using Statistical Package for the Social Sciences (SPSS) v19. Basic descriptive statistics were performed. In order to identify factors significantly associated with H1N1 uptake, odds ratios and 95\% CIs were calculated using binary logistic regression among those offered the vaccine. Factors with a $P$ value $<0.05$ and clinical factors known to be associated with vaccine uptake (sex, ethnicity, chronic illness, and year of study) were then entered into multiple logistic regression analysis. Due to small numbers, smoking status was recategorised into "never" and "ever" smokers and ethnicity as "White" and "Non-white". For the perception of H1N1 severity question, "Quite severe", "Severe" and "Very severe" were merged together as "severe."

\section{Results}

3.1. Response Rate. We received 31 responses as a result of the initial email. After the reminder, the total number of respondents was 68 (14.1\% response rate). After the paperbased approach, where 481 questionnaires were distributed, $137(28.5 \%)$ were returned. The data from both methods were combined for analysis $(205,42.6 \%)$. Respondents with incomplete H1N1 vaccination status $(2 / 205)$ were excluded. In total, $203(42.2 \%)$ entries were included in the study.

3.2. Characteristics of the Survey Respondents. The characteristics of the survey respondents are shown in Table 1. Of the 203 participants, 126 respondents were offered the vaccine whilst 77 were not. The majority were females $[n=$ $148(72.9 \%)]$, and in their third year of medical school [93, [45.8\%]]. Previous uptake of seasonal influenza vaccine was low and amongst those who had received vaccine, $20(28.2 \%)$ had suffered side effects. Patterns were largely similar between those who were and were not offered the vaccine, but those offered were largely from year 3 and over, were more likely to be Asian, have a chronic illness and have 
TABLE 1: Characteristics of respondents.

\begin{tabular}{|c|c|c|c|c|}
\hline Factor & & $\begin{array}{c}\text { Vaccine offered group, } \\
n=126(\%)\end{array}$ & $\begin{array}{l}\text { Vaccine not offered group, } \\
n=77(\%)\end{array}$ & $\begin{array}{c}\text { Total } \\
n=203(\%)\end{array}$ \\
\hline \multirow{3}{*}{ Sex } & Male & $34(27.0)$ & $20(26.0)$ & $54(26.6)$ \\
\hline & Female & $92(73.0)$ & $56(72.7)$ & $148(72.9)$ \\
\hline & Missing data & & $1(1.3)$ & $1(0.5)$ \\
\hline \multirow{2}{*}{ Age (mean $(\mathrm{SD}))$} & & $21.5(1.8)$ & $21.2(2.4)$ & $21.4(2.1)$ \\
\hline & Missing data & 2 & 2 & 4 \\
\hline \multirow{6}{*}{ Ethnicity } & White & $77(61.1)$ & $63(81.8)$ & $140(69.0)$ \\
\hline & Asian & $28(22.2)$ & $9(11.7)$ & $37(18.2)$ \\
\hline & Chinese & $11(8.7)$ & $2(2.6)$ & $13(6.4)$ \\
\hline & Mixed & $2(1.6)$ & $0(0)$ & $2(1.0)$ \\
\hline & Other & $7(5.6)$ & $2(2.6)$ & $9(4.4)$ \\
\hline & Missing data & $1(0.8)$ & $1(1.3)$ & $2(1.0)$ \\
\hline \multirow{3}{*}{ Smoking status } & Never smoker & $116(92.1)$ & $69(89.6)$ & $185(91.1)$ \\
\hline & Ex-smoker & $3(2.4)$ & $2(2.6)$ & $13(6.4)$ \\
\hline & Smoker & $7(5.6)$ & $6(7.8)$ & $5(2.5)$ \\
\hline \multirow{4}{*}{ Chronic illness } & No & $107(84.9)$ & $70(90.9)$ & $177(87.2)$ \\
\hline & Yes & $19(15.1)$ & $7(9.1)$ & $26(12.8)$ \\
\hline & Asthma & $13(10.3)$ & $6^{\mathrm{a}}(7.8)$ & $19^{\mathrm{a}}(9.4)$ \\
\hline & Other & $6(4.8)$ & $4(5.2)$ & $9(4.4)$ \\
\hline \multirow{5}{*}{ Year of study } & $\mathrm{GEC}^{\mathrm{b}} 1$ & $0(0)$ & $6(7.8)$ & $6(3.0)$ \\
\hline & Year 2 & $10(7.9)$ & $43(55.8)$ & $53(26.1)$ \\
\hline & Year 3 & $83(65.9)$ & $10(13.0)$ & $93(45.8)$ \\
\hline & Year 4 & $16(12.7)$ & $5(6.5)$ & $21(10.3)$ \\
\hline & Year 5 & $17(13.5)$ & $13(16.9)$ & $30(14.8)$ \\
\hline \multirow{6}{*}{ Lives with susceptible individuals } & Under 16 & $7(5.6)$ & $2(2.6)$ & $9(4.4)$ \\
\hline & Pregnant & $1(0.8)$ & $1(1.3)$ & $2(1.0)$ \\
\hline & Over 65 & $5(4.0)$ & $1(1.3)$ & $6(3.0)$ \\
\hline & HCW & $20(15.9)$ & $12(15.6)$ & $32(15.8)$ \\
\hline & None of the above & $95(75.4)$ & $62(80.5)$ & $157(77.3)$ \\
\hline & Missing data & $1(0.8)$ & & \\
\hline \multirow{4}{*}{ Seasonal influenza vaccination history } & Never & $67(53.2)$ & $61(79.2)$ & $128(63.1)$ \\
\hline & This year & $35(27.8)$ & $5(6.5)$ & $40(19.7)$ \\
\hline & Previous years & $23(18.3)$ & $8(10.4)$ & $31(15.3)$ \\
\hline & Missing data & $1(0.8)$ & $3(3.9)$ & $4(2.0)$ \\
\hline \multirow{2}{*}{ H1N1 vaccine } & Accept/would accept & $62(49.2)$ & $49(63.6)$ & $111(54.7)$ \\
\hline & Decline & $64(50.8)$ & $28(36.4)$ & $92(45.3)$ \\
\hline \multirow{2}{*}{ Knows anyone who contracted H1N1 } & No & $32(27.8)$ & $28(36.4)$ & $60(29.6)$ \\
\hline & Yes & $94(74.6)$ & $49(63.6)$ & $143(70.4)$ \\
\hline
\end{tabular}

a 3 Respondents had both asthma and other chronic illness.

${ }^{\mathrm{b}} \mathrm{GEC}$ stands for Graduate Entry Course.

had seasonal influenza vaccination that season or previous seasons.

3.3. H1N1 Influenza Vaccination: Intended and Actual Uptake. Of the 126 respondents who were offered the $\mathrm{H} 1 \mathrm{~N} 1$ vaccine, $62(49.2 \%$ (95\% CI $40.2-58.3 \%))$ accepted the vaccine. Of the 77 not offered, 49 (63.6\% (95\% CI 51.9-74.3\%)) stated they would accept the vaccine if offered. Those not offered were significantly more likely $(P=0.046)$ to state that they would accept the vaccine compared to those offered (OR 1.8 (95\% CI 1.01-3.2)).

3.4. Reasons for Acceptance or Declination of Influenza Vaccine. The three most frequently quoted reasons given for acceptance amongst both those offered and not offered the vaccine (although in a slightly different order) were 
TABLE 2: Knowledge and attitude of medical students towards the H1N1 pandemic.

\begin{tabular}{|c|c|c|c|c|}
\hline \multicolumn{2}{|c|}{ Knowledge questions } & \multicolumn{3}{|c|}{ Respondents with correct answers, $n(\%)$} \\
\hline & & $\begin{array}{l}\text { Vaccine-offered group } \\
n=126(\%)\end{array}$ & $\begin{array}{l}\text { Vaccine-not-offered group } \\
n=77(\%)\end{array}$ & $\begin{array}{c}\text { Total } \\
n=203(\%)\end{array}$ \\
\hline \multirow{6}{*}{$\begin{array}{l}\text { Priority groups receiving } \\
\text { H1N1 vaccine }\end{array}$} & Answered correctly & $45(35.7)$ & $27(35.1)$ & $72(35.5)$ \\
\hline & Over $65 \sqrt{ }^{\mathrm{a}}$ & & & \\
\hline & Under 16 & & & \\
\hline & Pregnant women $\sqrt{ }$ & & & \\
\hline & Healthcare workers $\sqrt{ }$ & & & \\
\hline & People with chronic health conditions $\sqrt{ }$ & & & \\
\hline \multirow{5}{*}{$\begin{array}{l}\text { Methods of transmission of } \\
\text { H1N1 virus }\end{array}$} & Answered correctly & $30(23.8)$ & $17(22.1)$ & $47(23.2)$ \\
\hline & Cough/sneezes $\sqrt{ }$ & & & \\
\hline & Eating infected meat & & & \\
\hline & Direct contact with an infected person $\sqrt{ }$ & & & \\
\hline & Touching contaminated object $\sqrt{ }$ & & & \\
\hline \multirow{7}{*}{ Fatality rate of $\mathrm{H} 1 \mathrm{~N} 1$} & Answered correctly & $45(35.7)$ & $29(37.7)$ & $74(36.5)$ \\
\hline & $0.01 \% \sqrt{ }$ & & & \\
\hline & $0.1 \%$ & & & \\
\hline & $1 \%$ & & & \\
\hline & $10 \%$ & & & \\
\hline & $20 \%$ & & & \\
\hline & $50 \%$ & & & \\
\hline Attitude & & $n=126(\%)$ & $n=77(\%)$ & $n=203(\%)$ \\
\hline \multirow{2}{*}{ Perception of H1N1 severity } & Not severe & $59(46.8)$ & $35(45.5)$ & $94(46.3)$ \\
\hline & Quite severe/Severe/Very severe & $67(53.2)$ & $42(54.6)$ & $109(53.7)$ \\
\hline
\end{tabular}

$\sqrt{ }$ Indicates the correct answer for the knowledge questions.

to decrease the likelihood of getting H1N1 (86.2\% (50/58) and $77.5 \%(31 / 40)$, respectively), reduce transmission to patients $(75.9 \%(44 / 58)$ and $82.5 \%(33 / 40))$, and to decrease the likelihood of transmission to family members $(63.8 \%$ (37/58) and 72.5\% (29/40)), (Figure 1).

The main reason given for declination of the vaccine amongst those offered was worry about side effects $(67.9 \%$ $(36 / 53)$ ), followed by lack of information about vaccination (50.9\% (27/53)) and perceiving they were not at risk (45.3\% (24/53)), (Figure 2). However, a further key reason for having been offered but not actually having received the vaccination was "inconvenient timing" (35.8\% (19/53)). For those who were not offered the vaccine, the main reasons for intention to decline were perception that they were not at risk $(52.2 \%$ $(12 / 23))$, lack of information $(47.8 \%(11 / 23))$ and worry about side effects (43.5\% (10/23)), (Figure 2).

The three major reported extrinsic influences affecting actual $\mathrm{H} 1 \mathrm{~N} 1$ vaccine uptake were medical training (79.4\% (81/102)), DH recommendations $(52.9 \%$ (54/102)) and social influences $(50.0 \%(51 / 102))$. For those who had not been offered the vaccine, they also reported medical training and DH guidelines as important $(73.8 \%$ $(45 / 61)$ and $49.2 \%(30 / 61)$, resp.), although the third most important influence cited was the media $(39.3 \%(24 / 61))$ (Figure 3).
3.5. Knowledge Regarding H1N1 Pandemic. Table 2 describes the students' knowledge and attitudes about the swine flu epidemic. Only a third of the respondents correctly identified all the priority groups $(35.5 \%)$, and only $23.2 \%$ correctly identified methods of $\mathrm{H} 1 \mathrm{~N} 1$ virus transmission. Almost half of participants (59 $(46.8 \%))$ thought the swine flu epidemic was not severe. Level of knowledge and perceived severity were similar across both the students offered and those not offered the vaccine.

3.6. Determinants of H1N1 Vaccination Uptake. Table 3 presents the factors which affected actual vaccine uptake amongst those offered the vaccine. On univariate analysis, there was no significant difference in uptake between the sexes, amongst smokers compared with ever smokers, or among students living with "at risk" groups. Students of nonwhite ethnicity were significantly less likely to take up the vaccine (OR 0.4 (95\% CI 0.2-0.8)), although those reporting a chronic illness were more likely to do so (OR 3.4 (95\% CI 1.2-10.2)). Students in years 4 and 5 were more likely to receive the vaccine (OR 3.0 (95\% CI 1.3-7.1)), and those who were correct in at least one of the knowledge questions were also more likely to accept the vaccine (OR 2.6 (95\% CI 1.1$6.0)$ ). 


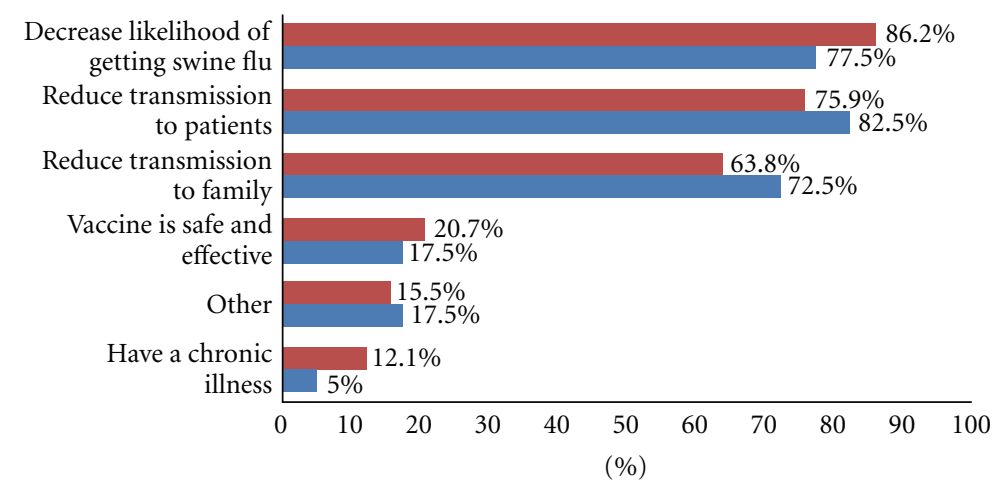

Vaccine offered $(n=58)$

Vaccine not offered (intention; $n=40$ )

FIGURE 1: Main reasons for H1N1 vaccine acceptance/intention to be vaccinated among medical students.

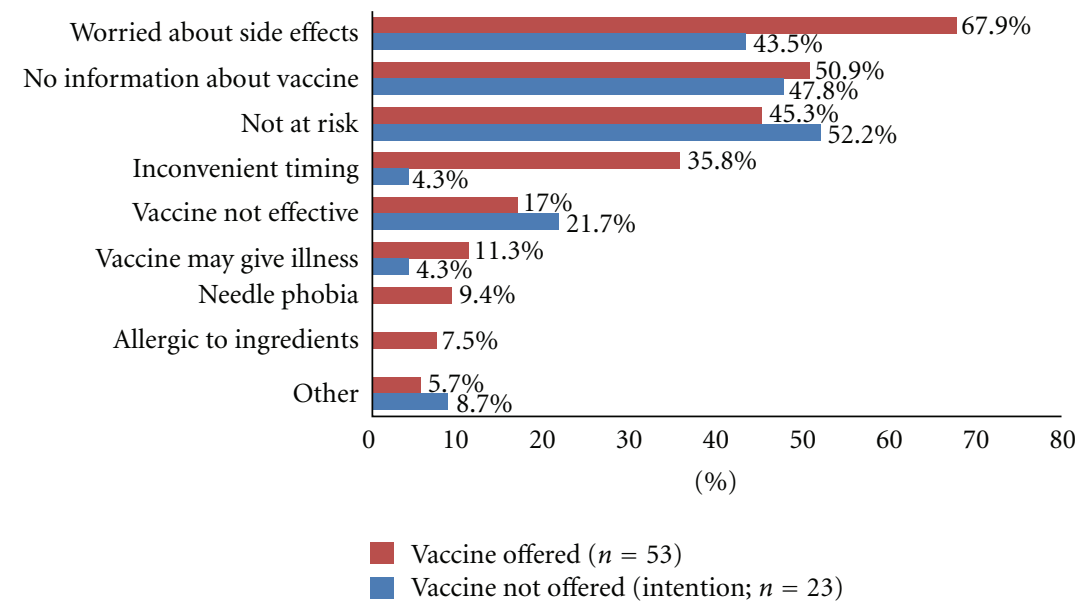

FigURE 2: Main reasons for H1N1 vaccine declination/intention to decline among medical students.

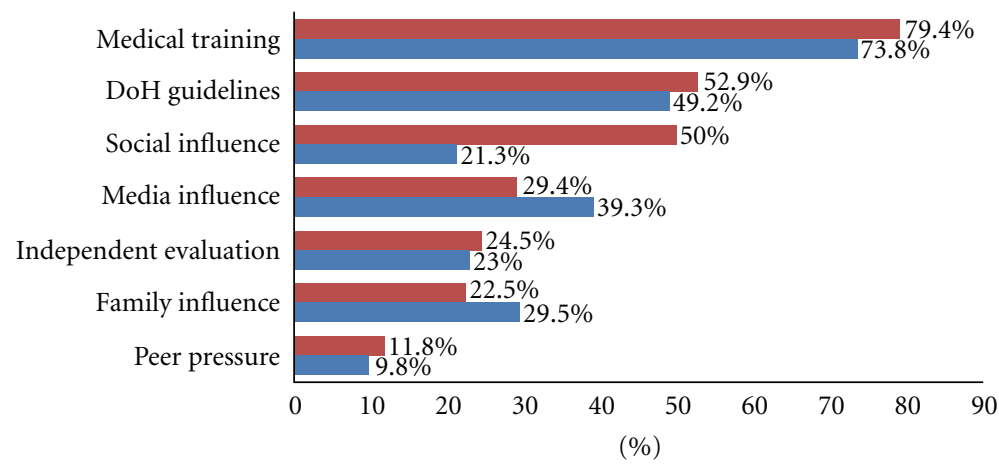

Vaccine offered $(n=102)$

Vaccine not offered (intention; $n=61$ )

FIGURE 3: Extrinsic factors affecting H1N1 vaccine uptake/intention to be vaccinated among medical students. 
TABLE 3: Determinants of vaccine uptake in the vaccine offered group.

\begin{tabular}{|c|c|c|c|c|c|}
\hline & iables & $\begin{array}{c}\text { Numbers receiving } \\
\text { vaccine }(\%)\end{array}$ & Univariate analysis & $\begin{array}{c}\text { Multivariate } \\
\text { analysis: model } 1^{\mathrm{a}}\end{array}$ & $\begin{array}{l}\text { Multivariate analysis: } \\
\text { model } 2 \text { including term } \\
\text { for previous seasonal } \\
\text { vaccination }^{\mathrm{b}}\end{array}$ \\
\hline \multirow{2}{*}{ Sex } & Male & $14(22.6)$ & 1.0 & 1.0 & 1.0 \\
\hline & Female & $48(77.4)$ & $0.6(0.3-1.4)$ & $1.1(0.4-2.6)$ & $1.4(0.4-4.7)$ \\
\hline \multirow{2}{*}{ Ethnicity } & White & $45(72.6)$ & 1.0 & 1.0 & 1.0 \\
\hline & Nonwhite & $17(27.4)$ & $0.4(0.2-0.8)$ & $0.4(0.2-0.8)$ & $0.3(0.1-0.8)$ \\
\hline \multirow{2}{*}{ Smoking status } & Never smoker & $58(93.5)$ & 1.0 & & \\
\hline & Ever smoker & $4(6.5)$ & $0.7(0.2-2.5)$ & & \\
\hline \multirow{2}{*}{ Chronic illness } & No & $48(77.4)$ & 1.0 & 1.0 & 1.0 \\
\hline & Yes & $14(22.6)$ & $3.4(1.2-10.2)$ & $3.5(1.0-12.1)$ & $1.8(0.3-9.9)$ \\
\hline \multirow{4}{*}{ Year of study } & GEC 1 and & $3(4.8)$ & $0.6(0.1-2.3)$ & $0.3(0.1-1.6)$ & $0.3(0.02-3.2)$ \\
\hline & Year 2 & $36(58.1)$ & 1.0 & 1.0 & 1.0 \\
\hline & Year 3 & $23(37.1)$ & $3.0(1.3-7.1)$ & $2.6(1.0-6.7)$ & $5.2(1.6-17.4)$ \\
\hline & Years 4 and 5 & & & & \\
\hline \multirow{2}{*}{$\begin{array}{l}\text { Lives with } 1 \text { of more } \\
\text { risk groups }\end{array}$} & No & $49(79.0)$ & 1.0 & & \\
\hline & Yes & $13(21.0)$ & $0.7(0.3-1.6)$ & & \\
\hline \multirow{2}{*}{$\begin{array}{l}\text { Seasonal influenza } \\
\text { vaccination history }\end{array}$} & Never & $22(35.5)$ & 1.0 & & 1.0 \\
\hline & Previous years & $10(16.1)$ & $1.6(0.6-4.1)$ & & $3.0(0.8-10.8)$ \\
\hline \multirow{2}{*}{$\begin{array}{l}\text { Knows anyone who } \\
\text { contracted H1N1 }\end{array}$} & No & $18(29.0)$ & 1.0 & & \\
\hline & Yes & $44(71.0)$ & $0.7(0.3-1.5)$ & & \\
\hline \multirow{2}{*}{$\begin{array}{l}\text { Number of correct } \\
\text { answers }\end{array}$} & None & $11(17.7)$ & 1.0 & 1.0 & 1.0 \\
\hline & At least 1 correct answer & $51(82.3)$ & $2.6(1.1-6.0)$ & $2.4(1.0-6.0)$ & $3.1(0.9-11.2)$ \\
\hline
\end{tabular}

${ }^{a}$ Adjusted for sex, ethnicity, year, of study and knowledge.

${ }^{\mathrm{b}}$ Adjusted for sex, ethnicity, year of study, knowledge, and previous seasonal influenza vaccine.

After adjustment for sex, ethnicity, year of study, presence of chronic illness and correct knowledge answers (model 1), students of non-white ethnicity remained as an important independent negative predictor of vaccine uptake (OR 0.4 (95\% CI 0.2-0.8)). Having a chronic illness (OR $3.4(95 \%$ CI 1.2-10.2)), being in years 4 or 5 (OR 3.0 (95\% CI 1.3$7.1)$ ) and having accurate knowledge on the $\mathrm{H} 1 \mathrm{~N} 1$ pandemic (OR 2.6 (95\% CI 1.1-6.0)) were positive predictors of vaccine uptake although they were of borderline significance.

The addition of previous seasonal vaccination to the multivariate model suggested that prior influenza vaccination might be a predictor of vaccine uptake, but was not statistically significant and may be explained partly by the presence of chronic illness.

3.7. Future Seasonal Influenza Vaccination. When asked, students who had actually received the $\mathrm{H} 1 \mathrm{~N} 1$ vaccine were three times more likely (OR 3.1 (95\% CI 1.2-7.7)) to say that they would accept the seasonal influenza vaccination in the future compared to respondents who declined the HIN1 vaccine.

\section{Discussion}

4.1. Main Findings of This Study. The H1N1 vaccine uptake among medical students was $49.2 \%$ and intended uptake was $63.3 \%$. This uptake is higher than the $40.3 \% \mathrm{H} 1 \mathrm{~N} 1$ vaccine uptake among frontline healthcare workers overall in England in 2009/10 although the figure is more similar to general practitioners' uptake (50.1\%) [9]. It is also noted that this uptake rate is substantially higher than the seasonal influenza vaccine uptake rate amongst HCW of $16.5 \%$ in $2008 / 9,26.4 \%$ in $2009 / 10$ [9], and even the improved postpandemic levels of $34.7 \%$ in the winter season of 2010/11 [16]. Studies in other countries found $\mathrm{H} 1 \mathrm{~N} 1$ vaccine uptake rates among medical students varied between $8 \%$ in Greece [22] to $93 \%$ in Sweden [23].

Main barriers to uptake included fear of side effects, lack of vaccine information, lack of perceived risk, and inconvenience. Main reasons for acceptance were to protect themselves, patients, and family. The main influences on uptake were medical training, DH recommendation, and social influences (much of which would probably be from other medical personnel). Having a chronic illness, 4th/5th year of study, and correct H1N1 knowledge were associated with uptake whilst non-white ethnicity was a negative predictor. Students in years $4 / 5$ were more likely to accept the vaccine as more years of clinical experience may have led to better understanding of the importance of vaccination and a greater sense of responsibility. This is consistent with the finding where those with better H1N1 knowledge 
were also more likely to accept the vaccine. Finally, H1N1 vaccine uptake predicted future seasonal influenza vaccine uptake.

4.2. What Is Already Known on This Topic. Consistent with the findings of our study, many studies of seasonal and pandemic influenza vaccine have demonstrated that the most common reasons for acceptance were for self-protection and patient protection whereas the main reasons for declining were fear of side effects and doubts of efficacy [11, 24-35]. Fear of side effects, the most frequently quoted barrier to uptake of H1N1 vaccine, could be due to media interest in the association between swine flu vaccine and Guillain Barré syndrome in 1976 [36, 37], and indeed media influence played an important role in the decision making of our study group, although not the main role. Inconvenient vaccine delivery was the fourth common reason for vaccine rejection in our study which accords with a past study of healthcare workers [38]. To increase the convenience of vaccine delivery, measures such as flexible appointment times, mobile carts, and electronic reminders could be implemented [39].

In contrast to findings of other studies that showed previous seasonal influenza vaccination as a positive predictor of the pandemic influenza vaccine uptake [11-15, 40], our study did not find a significant association; this is most likely because few students would have been offered the vaccine in the past except for those few with a chronic illness such as asthma.

Some studies have shown that ethnic minorities, particularly the black ethnic group, are less likely to accept the H1N1 or seasonal influenza vaccine as they are most likely to perceive the vaccine as unsafe [41-44]. Galarce et al. found that in the USA, blacks were most likely to have tried getting the H1N1 vaccine but found it unavailable [44]. There is little other data on uptake amongst South Asians, which is the most prevalent ethnic minority in our study and nonwhite ethnicity was shown to be a negative predictor of H1N1 vaccine uptake in our study.

4.3. What This Study Adds. As far as we are aware, this study is the first to report H1N1 vaccination uptake among medical students in the UK. As such, it sets the scene for potential future influenza vaccination campaigns to begin during medical school.

Uptake/intention to receive $\mathrm{H} 1 \mathrm{~N} 1$ vaccine amongst medical students appears to be higher than that of HCW (40.3\%) [9], although this is still below optimal levels. The barriers mentioned could be overcome by education about the efficacy and safety of the vaccine and reassurance that side effects are infrequent and usually mild. The formal medical training environment and guidance from the $\mathrm{DH}$ are clearly cited as the most important influencing factors and the medical course is a prime opportunity to exploit this, perhaps particularly in years 4 and 5 . It is also important to increase awareness that medical students are at greater risk of contracting $\mathrm{H} 1 \mathrm{~N} 1$ due to the nature and extent of their patient contact during placements. Informing students about the potential for transmission to patients should also become a priority in the effort to improve uptake. This is an important aim of interventions as our findings show that even a minimal knowledge about H1N1, its severity and transmission can increase uptake significantly.

Our study showed that subjects who accepted the H1N1 vaccine were three times more likely to state they would accept future seasonal influenza vaccines. This reinforces the importance of taking actions to increase $\mathrm{H} 1 \mathrm{~N} 1$ vaccine uptake amongst medical students. Acceptance of both pandemic and seasonal influenza vaccine is proven to be strongly associated with previous seasonal influenza vaccine uptake among HCW later in their careers [13, 14]. Hence, efforts to create a culture of seasonal influenza vaccination during student years are likely to impact on vaccine uptake in later years. Mandatory vaccination of healthcare workers against influenza is increasingly being called for on both moral and professional ethical grounds [45]. Perhaps medical school is the place to start.

4.4. Limitations of This Study. Valid responses were received from 201 students, who although were randomly selected, may not reflect the views and responses of all medical students in the UK. There were more year 3 respondents, which maybe because students from the same year as the authors (year 3) may be more willing to respond to the questionnaire. Many respondents failed to rank their responses to the reasons for uptake/declination which resulted in our data analysis changing from a weighted ranking as originally planned to a tally of reasons. However this data analysis approach is consistent with other published studies.

We attempted to establish any association between knowing someone who had contracted $\mathrm{H} 1 \mathrm{~N} 1$ and vaccine uptake. A significant majority (143 (70.4\%)) answered yes. This question could have focused specifically on first person contact and explored further how this could influence vaccination.

\section{Appendix}

\section{Questionnaire}

(1) Sex: $\square$ M $\square$ F

(2) Age at last birthday:

(3) Year of study: $\square$ 1st $\square$ GEC1 $\square$ 2nd $\square$ 3rd/GEC2 $\square$ 4th/GEC3 $\square$ 5th/GEC4

(4) Smoker: $\square$ Current regular $\square$ Current occasional $\square$ Ex-smoker

$\square$ Never smoker

(5) Do you have a long term medical condition? $\square$ No $\square$ if Yes-Please tick as appropriate below:

$\square$ Asthma $\square$ Diabetes $\square$ Epilepsy
$\square$ Hypertension
$\square \quad$ Inflammatory Bowel Disease $\square$ Other
Please state:


(6) Do you live with anyone who is: (Please tick any that apply)

$\square$ Under $16 \quad \square$ Pregnant $\square$ Over 65

$\square$ Healthcare professional

(7) Have you ever had seasonal flu vaccine? (Please tick any that apply)

$\square$ This year $\quad \square$ Last year $\quad \square$ Previous years
$\square$ Never

(8) If yes, have you had any side effects? $\square$ No $\square$ Yes Please state:

(9) Would you have a seasonal flu vaccine in the future? $\square$ Yes $\square$ No

(10) Who do you think are the priority groups for receiving the swine flu vaccine? Please select all relevant answers:

Over $65 \square$ Under $16 \quad \square$ Pregnant women $\square$ Healthcare workers $\square$ People with chronic health conditions

(11) How do you think swine flu is transmitted?

Please select all relevant answers:

$\square$ Coughs/Sneezes $\square$ Eating infected meat

$\square$ Direct contact with an infected person

$\square$ Touching a contaminated object $\square$ Other Please state:

(12) How severe do you think is the swine flu pandemic?

Not severe $\quad \square$ Quite severe $\quad \square$ Severe
Very Severe

(13) What do you think is the swine flu case-fatality rate?

$\square 0.01 \% \quad \square 0.1 \% \quad \square 1 \% \quad \square 10 \%$
$\square 20 \% \quad \square 50 \%$

(14) Do you know anyone who had swine flu?

$\square$ Yes $\quad \square$ No

(15) Have you been offered the swine flu vaccine?

$\square$ Yes, and I accepted the vaccine $\quad \square$ Yes, but I declined the vaccine

$\square$ No, but I will have the vaccine $\quad \square$ No, and I will not have the vaccine

(16) If you have accepted or will accept the vaccine, why? Please rank the 3 most relevant reasons in order, 1 being most important

$\square$ Reduce transmission to patients

$\square$ Reduce transmission to relatives/friends

$\square$ Decrease the likelihood of getting swine flu

$\square$ Vaccine is safe and effective

I have a chronic condition

Other

Please state:

(17) Which source of information influenced your decision on vaccination the most? Please rank the 3 most relevant reasons in order, 1 being most important

Social influence $\quad \square$ Media influence

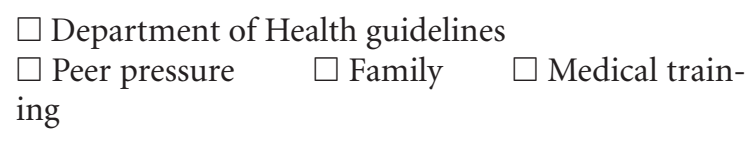

$\square$ Independent evaluation of scientific papers

(18) If you have declined or will decline the vaccine, why? Please rank the 3 most relevant reasons in order, 1 being most important

$\square$ Do not think myself at risk of swine flu

$\square$ Lack of information about the vaccine

$\square$ Do not think the vaccine is effective

$\square$ Needle phobia

$\square$ Worried about the side effects

$\square$ Timing of vaccination was inconvenient

$\square$ Vaccine might give me swine flu

$\square$ Allergies to constituents of vaccine

Other

Please state:

(19) Ethnicity: Please circle as appropriate if selecting "other" please state:

\begin{tabular}{|c|c|c|c|c|}
\hline White & Asian & Black & Mixed & $\begin{array}{c}\text { Other } \\
\text { ethnicities }\end{array}$ \\
\hline $\begin{array}{l}\text { White } \\
\text { British }\end{array}$ & Indian & Caribbean & $\begin{array}{c}\text { White/Black } \\
\text { Caribbean }\end{array}$ & Chinese \\
\hline $\begin{array}{l}\text { White } \\
\text { Irish }\end{array}$ & Pakistani & African & White/Asian & $\begin{array}{l}\text { Other } \\
\text { groups }\end{array}$ \\
\hline Other & $\begin{array}{c}\text { Bangladesh } \\
\text { Other } \\
\text { Asian }\end{array}$ & $\begin{array}{l}\text { Other } \\
\text { Black }\end{array}$ & $\begin{array}{l}\text { Other } \\
\text { mixed }\end{array}$ & \\
\hline
\end{tabular}

\section{Authors' Contribution}

G. D. Palaniandy, S. Mummadi, I. S. Chin, E. M. Aung, J. W. Hing, S. I. Lee did the literature review, designed the study, wrote the manuscript, collated the survey data, administered the survey and wrote the discussion; J. W. Hing, E. M. Aung and S. I. Lee performed statistical analyses; R. Jordan supervised the study. All authors, external and internal, had full access to all of the data (including statistical reports and tables) in the study and can take responsibility for the integrity of the data and the accuracy of the data analysis.

\section{Conflict of Interests}

The authors declare that they have no conflict of interests.

\section{Acknowledgment}

R. Jordan is funded by a National Institute for Health Research (NIHR) research fellowship. This study did not receive any other external funding.

\section{References}

[1] M. Chan, June 2009, World Health Organisation press statement, http://www.who.int/mediacentre/news/statements/ 2009/h1n1_pandemic_phase6_20090611/en/index.html. 
[2] Health Protection Agency, August 2011, Epidemiological report of pandemic (H1N1) 2009 in the UK, April 2009-May 2010, http://www.hpa.org.uk/webc/HPAwebFile/HPAweb_C/ 1284475321350.

[3] N. M. Ferguson, D. A. T. Cummings, C. Fraser, J. C. Cajka, P. C. Cooley, and D. S. Burke, "Strategies for mitigating an influenza pandemic," Nature, vol. 442, no. 7101, pp. 448-452, 2006.

[4] C. J. Luke and K. Subbarao, "Vaccines for pandemic influenza," Emerging Infectious Diseases, vol. 12, no. 1, 2006.

[5] L. Donaldson, December 2009, Further details about the H1N1 swine flu vaccination programme 2009-2010, http:// www.dh.gov.uk/prod_consum_dh/groups/dh_digitalassets/ documents/digitalasset/dh_104315.pdf.

[6] P. Orr, "Influenza vaccination for health care workers: a duty of care," Canadian Journal of Infectious Diseases, vol. 11, no. 5, pp. 225-226, 2000.

[7] S. Grant, REMINDER: Vaccinations against Swine Flu for Medical Students. E-mail received by all medical students at the University of Birmingham on 19/11/2009.

[8] R. Jordan, B. Wake, and J. Hawker, "Influenza vaccination of health care workers (HCW) to reduce influenza-related outcomes in high risk patients: a systematic review of clinical and cost effectiveness," Tech. Rep. 48, Department of Public Health and Epidemiology, University of Birmingham, Birmingham, UK, 2004.

[9] M. Sethi and R. Pebody, August, 2011, Pandemic H1N1 (Swine Flu) and Seasonal Influenza Vaccine Uptake amongst Frontline Healthcare Workers in England 2009/10, http:// www.dh.gov.uk/prod_consum_dh/groups/dh_digitalassets/@ dh/@en/@ps/documents/digitalasset/dh_121015.pdf.

[10] J. Mereckiene, S. Cotter, A. Nicoll et al., "National seasonal influenza vaccination survey in Europe, 2008," Eurosurveillance, vol. 13 , no. 43 , article 2.

[11] S. Vírseda, M. A. Restrepo, E. Arranz et al., "Seasonal and pandemic A (H1N1) 2009 influenza vaccination coverage and attitudes among health-care workers in a Spanish university hospital," Vaccine, vol. 28, no. 30, pp. 4751-4757, 2010.

[12] M. Pareek, T. Clark, H. Dillon, R. Kumar, and I. Stephenson, "Willingness of healthcare workers to accept voluntary stockpiled $\mathrm{H} 5 \mathrm{~N} 1$ vaccine in advance of pandemic activity," Vaccine, vol. 27, no. 8, pp. 1242-1247, 2009.

[13] H. Seale, R. Kaur, Q. Wang et al., "Acceptance of a vaccine against pandemic influenza A (H1N1) virus amongst healthcare workers in Beijing, China," Vaccine, vol. 29, no. 8, pp. 1605-1610, 2011.

[14] J. S. Y. Chor, S. K. Pada, I. Stephenson et al., "Seasonal influenza vaccination predicts pandemic $\mathrm{H} 1 \mathrm{~N} 1$ vaccination uptake among healthcare workers in three countries," Vaccine, vol. 29, no. 43 , pp. 7364-7369, 2011.

[15] M. S. Glaser, S. Chui, M. P. Webber et al., "Predictors of acceptance of H1N1 influenza vaccination by FDNY firefighters and EMS workers," Vaccine, vol. 29, no. 34, pp. 5675-5680, 2011.

[16] DH/HPA, October 2011, Seasonal influenza vaccine uptake amongst frontline healthcare workers (HCW) in England. Winter season 2010/2011 https://www.wp.dh.gov.uk/immunisation/files/2012/06/FluVaccine-Uptake_HCWs_acc2.pdf.

[17] E. Amodio, F. Tramuto, G. Maringhini, R. Asciutto, A. Firenze, and F. Vitale, "Are medical residents a, "core group" for future improvement of influenza vaccination coverage in health-care workers? A study among medical residents at the university hospital of Palermo (Sicily)," Vaccine, vol. 29, no. 45, pp. 81138117, 2011.

[18] S. L. Milunic, J. F. Quilty, D. M. Super, and G. H. Noritz, "Patterns of influenza vaccination among medical students,"
Infection Control and Hospital Epidemiology, vol. 31, no. 1, pp. 85-88, 2010.

[19] K. K. Mak, Y. F. Yiu, K. L. Ko et al., "Attitudes and perceptions of influenza vaccination among Hong Kong doctors and medical students before the 2009 pandemic," European Journal of Public Health. In press.

[20] W. C. Toy, J. E. Janosky, and S. B. Laird, "Influenza immunization of medical residents: knowledge, attitudes, and behaviors," American Journal of Infection Control, vol. 33, no. 8, pp. 473-475, 2005.

[21] R. K. Zimmerman, T. A. Santibanez, and J. E. Janosky, "What affects influenza vaccination rates among older patients? An analysis from inner-city, suburban, rural, and veterans affairs practices," American Journal of Medicine, vol. 114, no. 1, pp. 31-38, 2003.

[22] M. N. Mavros, P. K. Mitsikostas, I. G. Kontopidis, D. N. Moris, G. Dimopoulos, and M. E. Falagas, "H1N1v influenza vaccine in Greek medical students," European Journal of Public Health, vol. 21, no. 3, pp. 329-332, 2011.

[23] T. Faresjö, L. Arvidsson, P. Boberg, B. Hagert, E. A. Gursky, and T. Timpka, "Swedish nursing and medical students" high vaccination adherence during the influenza $A,(\mathrm{H} 1 \mathrm{~N} 1)$ pandemic 2009: insights for pandemic preparedness," Scandinavian Journal of Infectious Diseases, vol. 44, no. 3, pp. 237241, 2012.

[24] S. Wicker, H. F. Rabenau, H. W. Doerr, and R. Allwinn, "Influenza vaccination compliance among health care workers in a German university hospital," Infection, vol. 37, no. 3, pp. 197-202, 2009.

[25] F. W. O'Reilly, G. W. Cran, and A. B. Stevens, "Factors affecting influenza vaccine uptake among health care workers," Occupational Medicine, vol. 55, no. 6, pp. 474-479, 2005.

[26] A. P. Wodi, S. Samy, E. Ezeanolue et al., "Influenza vaccine: Immunization rates, knowledge, and attitudes of resident physicians in an urban teaching hospital," Infection Control and Hospital Epidemiology, vol. 26, no. 11, pp. 867-872, 2005.

[27] U. Heininger, M. Bächler, and U. B. Schaad, "Attitudes of pediatricians regarding influenza self-immunization: a survey in a Swiss university children's hospital," Pediatric Infectious Disease Journal, vol. 22, no. 5, pp. 391-394, 2003.

[28] M. W. Mah, N. A. Hagen, K. Pauling-Shepard et al., "Understanding influenza vaccination attitudes at a Canadian cancer center," American Journal of Infection Control, vol. 33, no. 4, pp. 243-250, 2005.

[29] H. Hakim, A. H. Gaur, and J. A. McCullers, "Motivating factors for high rates of influenza vaccination among healthcare workers," Vaccine, vol. 29, no. 35, pp. 5963-5969, 2011.

[30] G. J. Rubin, H. W. W. Potts, and S. Michie, "Likely uptake of swine and seasonal flu vaccines among healthcare workers. A cross-sectional analysis of UK telephone survey data," Vaccine, vol. 29, no. 13, pp. 2421-2428, 2011.

[31] F. Blasi, P. Palange, G. Rohde, T. Severin, G. Cornaglia, and R. Finch, "Healthcare workers and influenza vaccination: an ERS-ESCMID Web-based survey," Clinical Microbiology and Infection, vol. 17, no. 8, pp. 1223-1225, 2011.

[32] C. Boyeau, M. Tanguy, S. Pean, A. Delhumeau, and S. Fanello, "Seasonal and pandemic A, (H1N1) 2009 influenza vaccination coverage among health-care workers in a French university hospital," Santé Publique, vol. 23, no. 1, pp. 19-29.

[33] S. Grau, S. Luque, J. Pi-Sunyer et al., "Low adherence to 2009 pandemic influenza $\mathrm{A}(\mathrm{H} 1 \mathrm{~N} 1)$ vaccination program among health care workers of a medical centre during the pandemic phase," Enfermedades Infecciosas y Microbiologia Clinica, vol. 29, no. 4, pp. 269-275, 2011. 
[34] K. W. To, S. Lee, T. O. Chan, and S. S. Lee, "Exploring determinants of acceptance of the pandemic influenza $\mathrm{A}$ (H1N1) 2009 vaccination in nurses," American Journal of Infection Control, vol. 38, no. 8, pp. 623-630, 2010.

[35] H. C. Maltezou, X. Dedoukou, S. Patrinos et al., "Determinants of intention to get vaccinated against novel (pandemic) influenza A H1N1 among health-care workers in a nationwide survey," Journal of Infection, vol. 61, no. 3, pp. 252-258, 2010.

[36] G. Rachiotis, V. A. Mouchtour, and J. Kremastinou, "Low acceptance of vaccination against the 2009 pandemic influenza A, (H1N1) among healthcare workers in Greece," Eurosurveillance, vol. 15 , no. 6 , article 3 .

[37] J. G. Breman and N. S. Hayner, "Guillain-Barre syndrome and its relationship to swine influenza vaccination in Michigan, 1976-1977," American Journal of Epidemiology, vol. 119, pp. 880-889, 1984.

[38] H. G. Hollmeyer, F. Hayden, G. Poland, and U. Buchholz, "Influenza vaccination of health care workers in hospitalsa review of studies on attitudes and predictors," Vaccine, vol. 27, no. 30, pp. 3935-3944, 2009.

[39] R. Jordan and A. Hayward, "Should healthcare workers have the swine flu vaccine?" British Medical Journal, vol. 339, Article ID b3398, 2009.

[40] M. L. Boulton, A. M. Grossman, R. Potter, P. A. Vranesich, and J. Clayton, "Assessing the relationship between seasonal and $\mathrm{H} 1 \mathrm{~N} 1$ influenza vaccination status in Michigan children, 2009-2010," Public Health Reports, vol. 126, supplement 2, pp. 70-77.

[41] P. L. Hebert, K. D. Frick, R. L. Kane, and A. M. McBean, "The causes of racial and ethnic differences in influenza vaccination rates among elderly medicare beneficiaries," Health Services Research, vol. 40, no. 2, pp. 517-537, 2005.

[42] L. B. Myers and R. Goodwin, "Determinants of adults' intention to vaccinate against pandemic swine flu," $B M C$ Public Health, vol. 11, article 15, 2011.

[43] M. Hennessy-Fiske, Times/USC poll finds majority of California's registered voters have no plans to get $\mathrm{H} 1 \mathrm{~N} 1$ vaccine. Los Angeles Times, http://latimesblogs.latimes.com/ lanow/2009/11/timesusc-poll-finds-majority-of-californiasregistered-voter-have-no-plans-to-get-h1n1-vaccine.html.

[44] E. M. Galarce, S. Minsky, and K. Viswanath, "Socioeconomic status, demographics, beliefs and $\mathrm{A}(\mathrm{H} 1 \mathrm{~N} 1)$ vaccine uptake in the United States," Vaccine, vol. 29, no. 32, pp. 5284-5289, 2011.

[45] A. Caplan, "Time to mandate influenza vaccination in healthcare workers," The Lancet, vol. 378, no. 9788, pp. 310-311, 2011. 


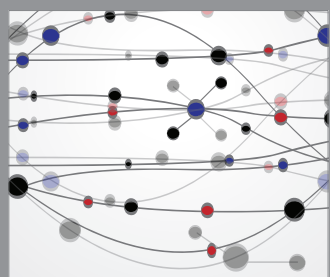

The Scientific World Journal
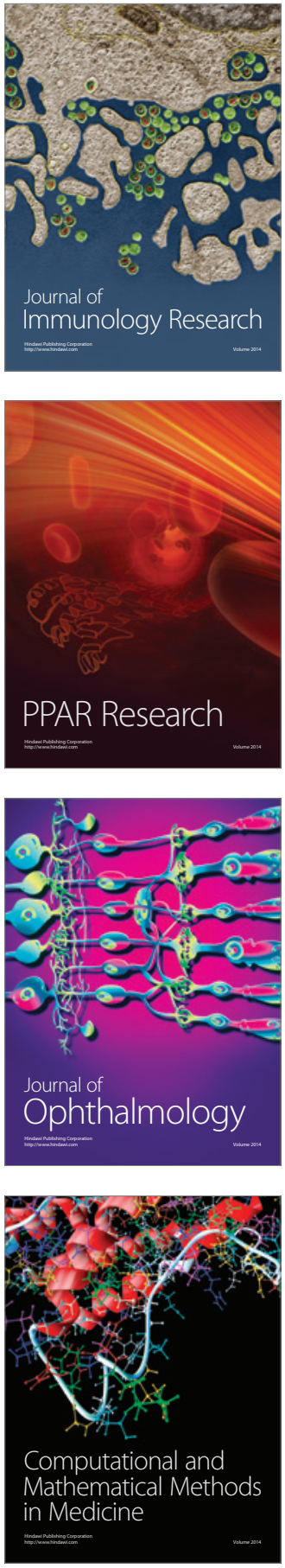

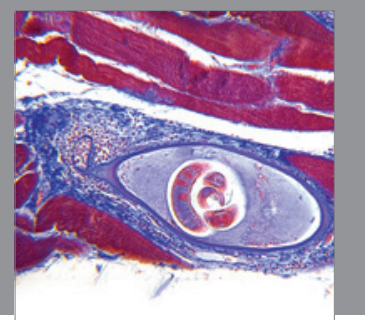

Gastroenterology

Research and Practice
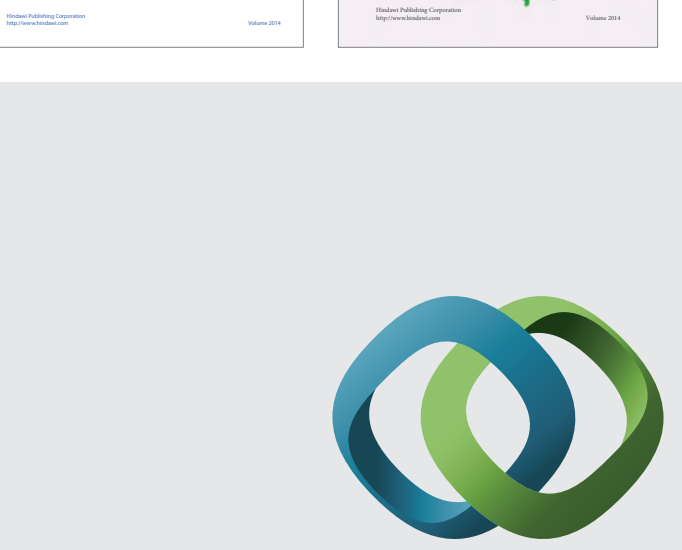

\section{Hindawi}

Submit your manuscripts at

http://www.hindawi.com
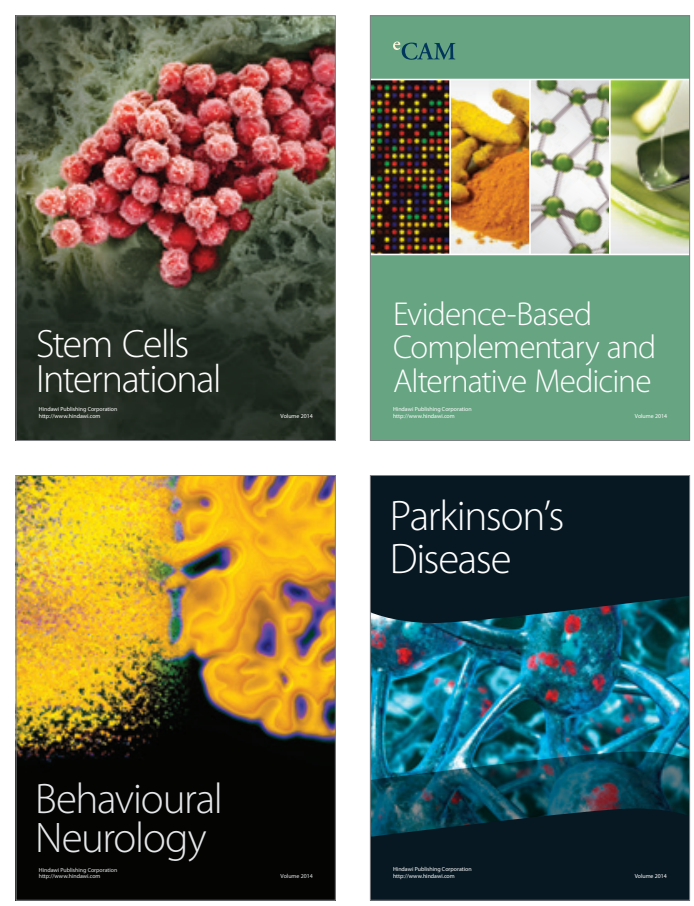

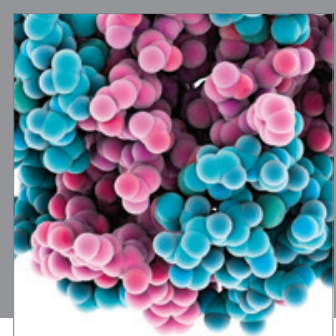

Journal of
Diabetes Research

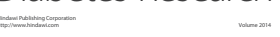

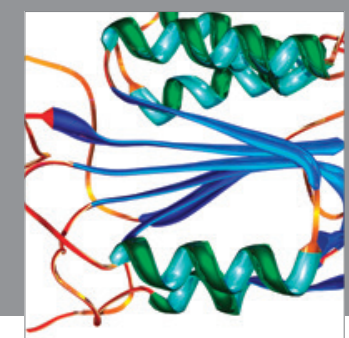

Disease Markers
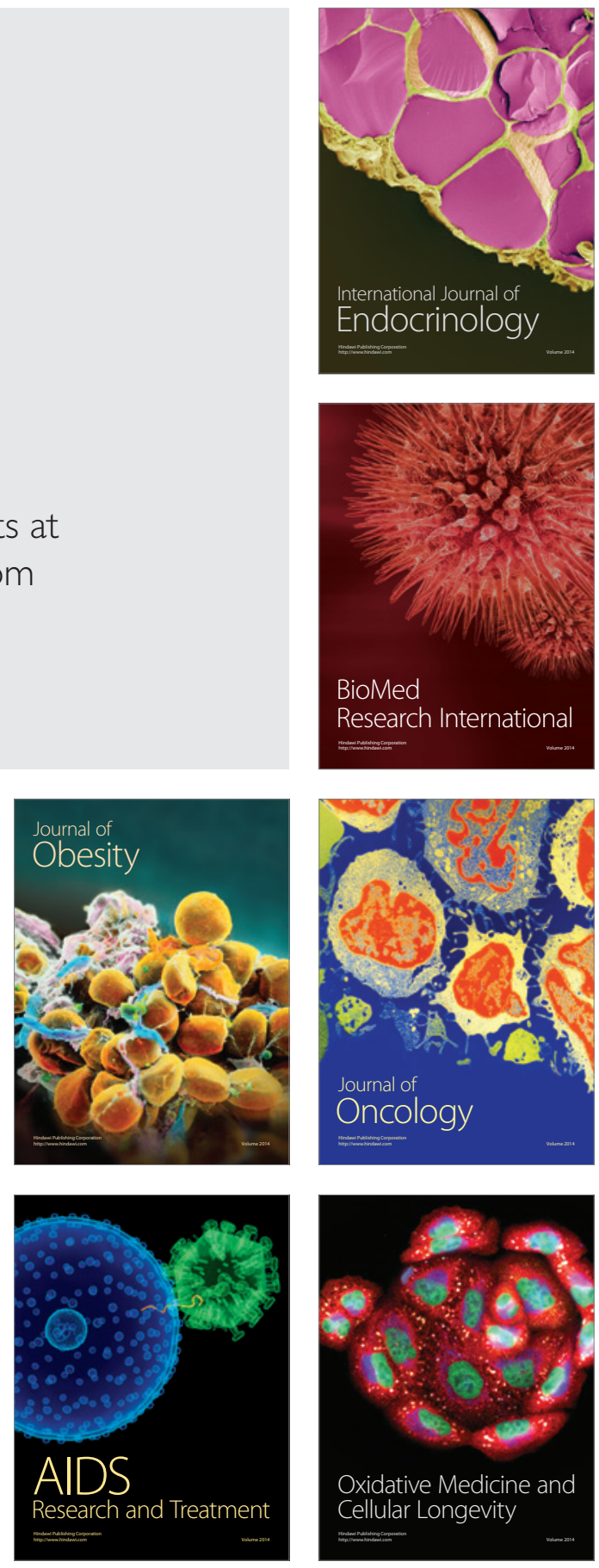